\title{
Effects of Sodium Thiosulfate on Vascular Calcification in End-Stage Renal Disease: A Pilot Study of Feasibility, Safety and Efficacy
}

\author{
Santhosh Jay Mathews ${ }^{a}$ Lisa de las Fuentes ${ }^{a}$ Prashanth Podaralla ${ }^{b}$ \\ Anton Cabellon $^{b}$ Sijie Zheng ${ }^{b}$ Andrew Bierhals ${ }^{c}$ Karen Spence ${ }^{a}$ \\ Eduardo Slatopolsky ${ }^{b}$ Victor G. Davila-Roman ${ }^{a} \quad$ James A. Delmez ${ }^{b}$ \\ ${ }^{a}$ Cardiovascular Imaging and Clinical Research Core Laboratory and Cardiovascular Division, \\ ${ }^{b}$ Division of Nephrology, and 'Mallinckrodt Institute of Radiology, Washington University School of Medicine, \\ St. Louis, Mo., USA
}

\section{Key Words}

Hemodialysis $\cdot$ Sodium thiosulfate $\cdot$ Vascular calcification

\begin{abstract}
Background and Objectives: Vascular calcification is a major contributor to morbidity and mortality in hemodialysis. The objective of this pilot study was to determine the feasibility, safety and efficacy of sodium thiosulfate (STS) in the progression of vascular calcification in hemodialysis patients. Methods: Chronic hemodialysis patients underwent a battery of cardiovascular tests. Those with coronary artery calcium (Agatston scores $>50$ ) received intravenous STS after each dialysis for 5 months $(n=22)$ and the tests were repeated. Changes in MDCT-determined calcification were assessed as the mean annualized rate of change in 3 vascular beds (coronary, thoracic and carotid arteries) and in L1-L2 vertebral bone density. Results: Although individual analyses showed coronary artery calcification progression in $14 / 22$ subjects, there was no progression in the mean annualized rate of change of vascular calcification in the entire group. The L1-L2 vertebral bone density showed no changes. There were no correlations between rates of progression
\end{abstract}

of vascular calcification and phosphorus, fetuin or C-reactive protein levels. Changes in coronary artery calcification scores correlated with those of the thoracic aorta. Conclusion: STS treatment is feasible, appears safe and may decrease the rate of progression of vascular calcification in hemodialysis patients. A large, randomized, controlled trial is warranted.

Copyright $\odot 2011$ S. Karger AG, Basel

\section{Introduction}

Cardiovascular disease is the leading cause of morbidity and mortality in patients undergoing chronic hemodialysis (HD) for end-stage renal disease (ESRD) [1]. Vascular calcification, an active and progressive process involving ectopic osteogenesis, has been implicated as an important mediator of the increase cardiovascular morbidity and mortality [2]. Factors promoting vascular calcification include phosphorus accumulation, uremic toxins, oxidative stress and inflammation, which are opposed by inhibitors of calcification such as fetuin-A [3].

Sodium thiosulfate [STS $\left(\mathrm{Na}_{2} \mathrm{~S}_{2} \mathrm{O}_{3}\right)$ ] has been used to treat calcific uremic arteriolopathy (CUA or calciphylax-

\section{KARGER}

๑ 2011 S. Karger AG, Basel

Fax +41613061234 E-Mail karger@karger.ch www.karger.com www.karger.com/ajn
James A. Delmez, MD

Division of Nephrology, Washington University School of Medicine

Campus Box 8129, 660 S. Euclid Ave.

St. Louis, MO 63110 (USA)

Tel. +1 314362 7207, Fax +1 314747 3743,E-Mail jdelmez@dom.wustl.edu 
is), a process that involves medial calcification of small arteries and arterioles of patients with ESRD. Postulated mechanisms of action of STS in CUA are formation of highly soluble calcium thiosulfate complexes and potent antioxidant properties $[4,5]$.

The purpose of the current study was to determine the feasibility, safety and efficacy of short-term STS treatment of HD patients on calcification in 3 vascular beds (coronary and carotid arteries, and the thoracic aorta) and on L1-L2 vertebral bone density.

\section{Patients and Methods}

\section{Study Population}

Forty-eight patients undergoing chronic HD treatments at Washington University Medical Center were enrolled. Inclusion criteria were: (1) ESRD on HD, (2) compliance with treatments as subjectively assessed by the investigators, (3) willingness to undergo intravenous STS treatments for 5 months if eligible and (4) ability to give informed consent approved by the Institutional Review Board at Washington University School of Medicine in accordance with the Declaration of Helsinki. Exclusion criteria were: (1) age $<18$ years, (2) life expectancy $<6$ months, (3) pregnancy, (4) current or recent ( $<12$ months) treatment with corticosteroids, and (5) weight $>350 \mathrm{lbs}$ (due to inability to perform MDCT). After enrollment, all eligible subjects underwent MDCT for measurement of the coronary artery calcium (CAC) score; only those with a CAC score $>50$ Agatston units were eligible for STS treatment.

\section{Standard Medications in Dialysis Units}

Sevelamer hydrochloride was used to maintain phosphorus levels $<5.5 \mathrm{mg} / \mathrm{dl}$. Total elemental calcium did not exceed 1.5 g/day. Ergocalciferol $\geq 50,000$ IU monthly was used to maintain 25 -hydroxy vitamin D levels $>30 \mathrm{ng} / \mathrm{ml}$. Paricalcitol was used for parathyroid hormone $(\mathrm{PTH})$ levels $>300 \mathrm{pg} / \mathrm{ml}$. All patients maintained $\mathrm{Kt} / \mathrm{V}$ values $>1.3$ and were treated with high-flux dialyzers; dialysate calcium was $2.5 \mathrm{mEq} / \mathrm{l}$.

\section{STS Treatment Protocol}

The study was registered with Clinical Trials (www.clinicaltrial.org), identifier number: NCT00568399. Patients were scheduled to receive a total of 60 STS treatments (intravenous $25 \%$ solution; American Reagent Laboratories, Shirley, N.Y., USA) 3 times per week over a 5-month period, starting at a dose of $12.5 \mathrm{~g}$, administered over $30 \mathrm{~min}$ after each HD treatment. The dose was increased weekly to $18.75 \mathrm{~g}$ and then to $25 \mathrm{~g}$, as tolerated. Since dialysis removes STS, 1 subject who underwent dialysis 4 times a week received a total of 80 treatments over the 5-month period.

\section{Measurements Obtained before and during Treatment}

Data on demographics, primary renal disease, comorbid conditions and medications were obtained from hospital and dialysis records at the time of testing. Blood pressure measurements were obtained at the time of the echocardiogram. The calcium, phosphorus, bicarbonate and anion gap values were the mean of each of the monthly levels 4 months prior to treatment and the last 4 months during treatment with STS. Routine laboratory measurements were performed by Spectra Laboratories (Rockleigh, N.J., USA). Serum fetuin-A (Epitope Inc., San Diego, Calif., USA), high-sensitivity C-reactive protein (Life Diagnostics, West Chester, Pa., USA), and PTH (Spectra Laboratories) levels were measured within a month prior to and at the end of STS treatment.

MDCT Imaging for Assessment of Vascular Calcification and Lumbar Bone Density

A 64-slice MDCT scanner (Somatom Sensation 64; Siemens Medical Systems, Forchheim, Germany) measured calcium scores and volumes by the Agatston method [6]. After initial scout imaging, the scan fields were set for the neck, chest and abdomen for measurement of arterial calcification in the carotids (from the arch to $1 \mathrm{~mm}$ above the carotid bifurcation), coronary arteries, aortic arch and thoracic aorta (to the top endplate of the T12 vertebral body), and bone density (of L1 and L2 vertebral bodies). The scan parameters included $24 \times 1.2 \mathrm{~mm}$ collimation, 3-mm slice thickness, 0.37 -second rotation time, spiral mode and $120 \mathrm{kVp}$ at $80 \mathrm{mAs}$ with reconstruction at $60 \%$ of the $\mathrm{R}-\mathrm{R}$ interval.

Vascular calcium scores and volumes were measured by use of commercially available software (Vitrea; Vital Images Inc., Minnetonka, Minn., USA) as previously described [6]. All images were randomly evaluated by 2 independent expert observers (S.J.M., A.B.) who were blinded to all clinical characteristics.

\section{Cardiac Structure and Function Evaluation by \\ Echocardiography}

Baseline echocardiography to assess cardiac structure and systolic/diastolic function was performed using a commerciallyavailable ultrasound system (Sequoia; Acuson-Siemens, Mountain View, Calif., USA) according to published guidelines [7]. All vascular and cardiac ultrasound studies were analyzed off-line by 2 blinded independent readers using commercially available software (ProSolv CardioVascular; Fujifilm Medical Systems, Stamford, Conn., USA) as previously described by our group [8].

Vascular Structure Evaluation by Carotid Ultrasound

Carotid ultrasound imaging was performed using the ultrasound system described above, with a $15-\mathrm{MHz}$ linear array transducer for measurement of carotid intima-media thickness, as previously described [9].

\section{Vascular Function Assessment}

Arterial vascular function was assessed using the SphygmoCor blood pressure analysis system (AtCor Medical, Sydney, N.S.W., Australia) for measurement of the augmentation index and pulse wave velocity as previously described [10].

\section{Statistical Analysis}

Variables are expressed as means $\pm \mathrm{SD}$. For analysis, progression of vascular calcification by MDCT was defined as the difference between the follow-up and baseline square root-transformed calcium volumes $\geq 2.5 \mathrm{~mm}^{3}$ per year. This method has been used previously to assess progression due to the $<1 \%$ likelihood of being due to variability between MDCT studies [11, 12]. Patients 
Table 1. Baseline characteristics of the study population

\begin{tabular}{|c|c|c|c|}
\hline & $\begin{array}{l}\text { Total } \\
(\mathrm{n}=22)\end{array}$ & $\begin{array}{l}\text { Non- } \\
\text { progressors } \\
(\mathrm{n}=8)\end{array}$ & $\begin{array}{l}\text { Progressors } \\
(\mathrm{n}=14)\end{array}$ \\
\hline \multicolumn{4}{|l|}{ Demographics } \\
\hline Age, years & $59 \pm 10$ & $60 \pm 8$ & $59 \pm 11$ \\
\hline BMI & $30 \pm 8$ & $29 \pm 4$ & $31 \pm 10$ \\
\hline Gender, $\%$ male & 64 & 88 & 50 \\
\hline \multicolumn{4}{|l|}{ Race and ethnicity } \\
\hline African American, \% & 86 & 88 & 86 \\
\hline \multicolumn{4}{|l|}{ Hemodynamics } \\
\hline $\mathrm{HR}, \mathrm{bpm}$ & $77 \pm 16$ & $75 \pm 16$ & $78 \pm 16$ \\
\hline $\mathrm{SBP}, \mathrm{mm} \mathrm{Hg}$ & $129 \pm 24$ & $121 \pm 20$ & $133 \pm 26$ \\
\hline $\mathrm{DBP}, \mathrm{mm} \mathrm{Hg}$ & $73 \pm 12$ & $67 \pm 7$ & $76 \pm 13$ \\
\hline \multicolumn{4}{|l|}{ Comorbidity, \% } \\
\hline HTN & 95 & 100 & 93 \\
\hline Ischemia & 77 & 75 & 79 \\
\hline $\mathrm{CHF}$ & 27 & 25 & 29 \\
\hline PAD & 14 & 25 & 7 \\
\hline $\mathrm{DM}$ & 45 & 50 & 43 \\
\hline Statin & 59 & 63 & 57 \\
\hline \multicolumn{4}{|l|}{ Smoking history, \% } \\
\hline Never & 41 & 38 & 27 \\
\hline Previous & 23 & 25 & 21 \\
\hline Current & 36 & 38 & 36 \\
\hline \multicolumn{4}{|l|}{ Cause of ESRD, \% } \\
\hline $\mathrm{DM}$ & 41 & 50 & 36 \\
\hline HTN & 45 & 50 & 43 \\
\hline SLE & 9 & 0 & 14 \\
\hline PCKD & 5 & 0 & 5 \\
\hline \multicolumn{4}{|l|}{ Hemodialysis } \\
\hline Vintage, months & $67 \pm 52$ & $70 \pm 68$ & $65 \pm 44$ \\
\hline \multicolumn{4}{|l|}{ Calcium scoring } \\
\hline \multirow{2}{*}{ Coronary arteries } & $1,743 \pm$ & $1,622 \pm$ & $1,813 \pm$ \\
\hline & $\begin{array}{l}1,487 \\
5,357 \pm 4,885\end{array}$ & $\begin{array}{l}1,114 \\
3,231 \pm 3,396\end{array}$ & $\begin{array}{l}1,700 \\
6,572 \pm 5,289\end{array}$ \\
\hline Carotid arteries & $453 \pm 479$ & $370 \pm 481$ & $501 \pm 489$ \\
\hline Bone density (L1 and L2) & $\begin{array}{l}67,154 \pm \\
16,911\end{array}$ & $\begin{array}{l}71,045 \pm \\
15,185\end{array}$ & $\begin{array}{l}64,932 \pm \\
17,978\end{array}$ \\
\hline
\end{tabular}

All $\mathrm{p}$ values are nonsignificant. $\mathrm{HR}=$ Heart rate; $\mathrm{SBP}=$ systolic blood pressure; $\mathrm{DBP}=$ diastolic blood pressure; $\mathrm{HTN}=$ hypertension; $\mathrm{CHF}=$ congestive heart failure; $\mathrm{PAD}=$ peripheral arterial disease; $\mathrm{DM}=$ diabetes mellitus; SLE = systemic lupus erythematosus; $\mathrm{PCKD}=$ polycystic kidney disease.

were grouped based on their annualized scores into nonprogressors $\left(<2.5 \mathrm{~mm}^{3} /\right.$ years $)$ and progressors ( $\geq 2.5 \mathrm{~mm}^{3} /$ years $)$. Comparisons between the groups were calculated using WilcoxonMann-Whitney tests. Paired tests for differences between preand post-treatment were calculated using the Wilcoxon signedrank test. The correlations between coronary annualized scores
Table 2. ESRD-related measures

\begin{tabular}{lcc}
\hline & Pre-STS & Post-STS \\
\hline Phosphorus, mg/dl* & $5.8 \pm 1.2$ & $5.8 \pm 1.1$ \\
Calcium, mg/dl* & $9.0 \pm 0.5$ & $9.2 \pm 0.5$ \\
Bicarbonate, mEq/1** & $25.0 \pm 2.6$ & $23.4 \pm 2.1$ \\
Anion gap, mEq/1*** & $16.2 \pm 2.4$ & $21.8 \pm 3.2$ \\
PTH, pg/ml* & $354 \pm 296$ & $357 \pm 256$ \\
Fetuin, g/l* & $0.47 \pm 0.12$ & $0.44 \pm 0.11$ \\
hsCRP, ug/ml* & $12.4 \pm 12.1$ & $19.2 \pm 21.6$ \\
\hline
\end{tabular}

${ }^{*} \mathrm{p}$ value nonsignificant; ${ }^{* *} \mathrm{p} \leq 0.05 ;{ }^{* * *} \mathrm{p} \leq 0.001$.

hsCRP $=$ High-sensitivity C-reactive protein.

and annualized scores for the aorta, carotids and lumbar spine were calculated using Spearman's rank-order coefficients. Statistical analysis was performed using SAS (v. 9.2; SAS Institute, Cary, N.C., USA). All tests were 2 -tailed; $\mathrm{p}<0.05$ was considered statistically significant.

\section{Results}

\section{Study Population}

Forty-eight enrolled subjects underwent the initial cardiovascular tests; 10 were excluded prior to STS treatment due to low CAC scores ( $<50$ Agatston units), and 1 was excluded due to traumatic hip fracture. Of the $37 \mathrm{sub}-$ jects who were initiated on STS treatment, 2 died (1 each of sepsis and retroperitoneal bleeding), 5 withdrew consent due to nausea and 8 discontinued therapy because of time constraints. Hence, 22 subjects completed the entire protocol.

The baseline characteristics of the study population $(n=22)$ and for those grouped by nonprogressor $(n=8)$ versus progressor $(n=14)$ status are shown in table 1 . The majority of subjects (86\%) were African American, 45\% were diabetics. At baseline, there were no significant differences for any variable between nonprogressors and progressors, although the progressors tended to have higher vascular calcium and vertebral bone density scores.

\section{Treatment with STS}

STS infusions at the dose of $25 \mathrm{~g} /$ treatment were associated with nausea and vomiting by all despite antiemetic therapy. This was likely due to the short infusion period and administering the drug after HD treatments, thus eliminating dialytic removal. A lower amount was well tolerated with a maintenance dose of $12.5 \mathrm{~g} /$ treat- 
Table 3. Vascular ultrasound and echocardiographic measurements pre- versus post-STS

\begin{tabular}{lcc}
\hline & Pre-STS & Post-STS \\
\hline Vascular structure & & \\
$\quad$ Carotid IMT, mm & $0.91 \pm 0.18$ & $0.92 \pm 0.24$ \\
LV structure & & \\
LVM/Ht $2.7\left(\mathrm{~g} / \mathrm{m}^{2.7}\right)$ & $58 \pm 18$ & $58 \pm 20$ \\
LV systolic function & & \\
LVEF, \% & $57 \pm 13$ & $56 \pm 13$ \\
S', cm/s & $7.6 \pm 1.1$ & $7.6 \pm 1.3$ \\
LV diastolic function & & \\
E/A ratio & $1.2 \pm 0.5$ & $1.2 \pm 0.5$ \\
DT, ms & $205 \pm 40$ & $207 \pm 59$ \\
IVRT, ms & $82 \pm 23$ & $72 \pm 19$ \\
E', cm/s & $9.1 \pm 2.2$ & $9.4 \pm 2.5$ \\
PWV, m/s (n = 20) & $12 \pm 5$ & $13 \pm 7$ \\
PWA (n=16) & & \\
Augmentation index & $23 \pm 15$ & $23 \pm 12$ \\
Augmentation index at HR 75 & $22 \pm 14$ & $23 \pm 10$ \\
\hline
\end{tabular}

All $\mathrm{p}$ values are nonsignificant.

IMT = Intima-media thickness; LV = left ventricle; $L V M=$ left ventricular mass; $\mathrm{Ht}=$ height; $\mathrm{LVEF}=$ left ventricular ejection fraction; $\mathrm{DT}=$ deceleration time; $\mathrm{IVRT}=$ isovolumic relaxation time; PWV = pulse wave velocity; PWA = pulse wave analysis.

ment in 16 patients and $18.75 \mathrm{~g} /$ treatment in 6 patients. There were 12 hospital admissions in the 48 subjects: atypical chest pain $(n=3)$, gastrointestinal bleeding $(n=$ $1)$, influenza $(\mathrm{n}=1)$, pneumonia $(\mathrm{n}=1)$, back abscess $(\mathrm{n}=1)$, congestive heart failure exacerbation $(\mathrm{n}=2)$, uncontrolled hypertension $(\mathrm{n}=2)$ and asthma exacerbation $(n=1)$. None of the hospitalizations or deaths were considered to be related to STS treatment as judged by an independent safety committee.

The anion gap increased from $16.2 \pm 2.4$ to $21.8 \pm 3.2$ $\mathrm{mEq} / \mathrm{l}(\mathrm{p} \leq 0.001)$ and serum bicarbonate levels decreased from $25.0 \pm 2.6$ to $23.4 \pm 2.1 \mathrm{mEq} / \mathrm{l}(\mathrm{p} \leq 0.05)$, likely due to accumulation of thiosulfate. There were no significant changes in heart rate and blood pressure or serum levels of phosphorus, calcium, PTH, fetuin or high-sensitivity C-reactive protein before and after treatment in the entire group (table 2), or between nonprogressors and progressors for any measure. There were no significant changes (pre- vs. post-STS treatment) in vascular structure (carotid intima-media thickness) and function (augmentation index, pulse wave velocity), or cardiac structure and systolic/diastolic function with STS treatment (table 3).
Table 4. Annualized calcium volumes

\begin{tabular}{llrll}
\hline & Total & $\begin{array}{l}\text { Nonpro- } \\
\text { gressors } \\
(\mathrm{n}=8)\end{array}$ & $\begin{array}{l}\text { Pro- } \\
\text { gressors } \\
(\mathrm{n}=14)\end{array}$ & $\mathrm{p}$ \\
\hline $\begin{array}{l}\text { Coronary arteries } \\
\text { Thoracic aorta }\end{array}$ & $6.6 \pm 9.7$ & $-3.2 \pm 3.7$ & $12.3 \pm 7.1$ & 0.001 \\
$\begin{array}{l}\text { Carotid arteries } \\
\begin{array}{l}\text { Bone density } \\
(\text { L1 and L2) }\end{array}\end{array}$ & $1.9 \pm 8.0$ & $3.2 \pm 8.6$ & $0.3 \pm 7.4$ & NS \\
\hline \multicolumn{2}{c}{$1.3 \pm 15.9$} & $3.2 \pm 19.6$ & $0.3 \pm 14.2$ & NS \\
\hline \multicolumn{2}{c}{ NS = Nonsignificant. } & & & \\
\hline
\end{tabular}

Table 5. Annualized volumes and correlation with coronary calcification

\begin{tabular}{llll}
\hline & Mean \pm SD & \multicolumn{1}{c}{$\mathrm{r}$} & $\mathrm{p}$ \\
\hline Coronary arteries & $6.6 \pm 9.7$ & - & - \\
Thoracic aorta & $9.1 \pm 9.1$ & 0.61 & 0.003 \\
Carotid arteries & $1.9 \pm 8.0$ & -0.32 & 0.48 \\
Bone density (L1 and L2) & $1.3 \pm 15.9$ & 0.16 & 0.15 \\
\hline
\end{tabular}

Table 6. Intra- and interobserver reproducibility of volumes

\begin{tabular}{llll}
\hline & $\begin{array}{l}\text { Number } \\
\text { of studies }\end{array}$ & $\begin{array}{l}\text { Intraclass } \\
\text { correlation } \\
(\rho)\end{array}$ & $95 \%$ CI \\
\hline Observer 1 & & & \\
Coronary & 24 & 0.964 & $0.987-0.900$ \\
Aorta & 24 & 0.999 & $1.000-0.997$ \\
Carotid & 23 & 0.993 & $0.997-0.973$ \\
Bone & 22 & 0.997 & $0.999-0.991$ \\
Observer 1 vs. Observer 2 & & \\
Coronary & 44 & 0.993 & $0.995-0.972$ \\
Aorta & 44 & 0.991 & $0.996-0.976$ \\
Carotid & 44 & 0.924 & $0.967-0.811$ \\
Bone & 44 & 0.983 & $0.991-0.945$ \\
\hline
\end{tabular}

\section{Vascular Calcification and Lumbar Bone Density}

There were no significant differences in the mean annualized rates of change of the square root-transformed calcium volumes of the coronary, thoracic and carotid arteries or of the L1-L2 vertebral bone density for the entire group (fig. 1; table 4). Although there was consider- 


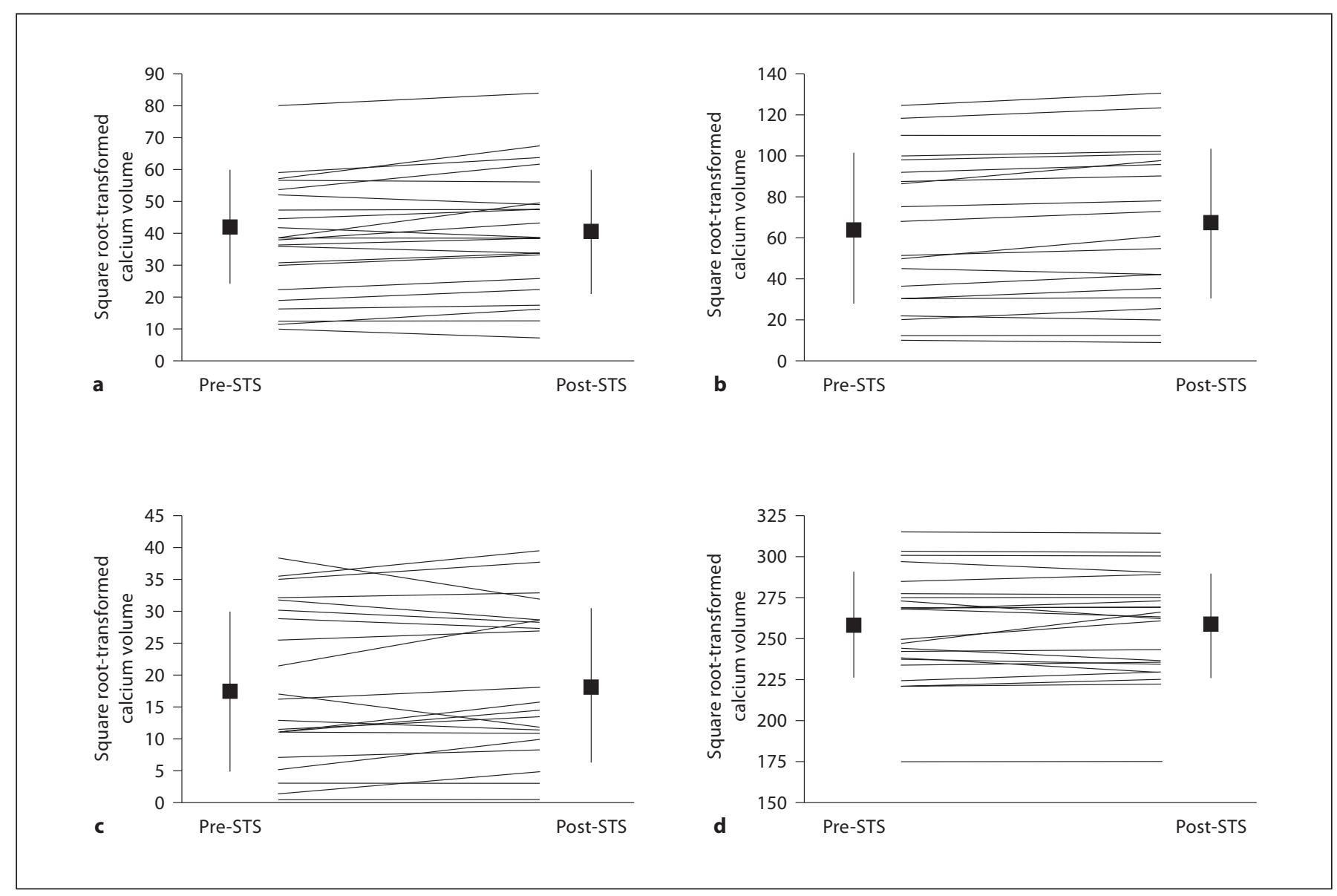

Fig. 1. Individual measurements of vascular calcification volume pre- and post-STS. a Coronary arteries. b Thoracic aorta. c Carotid arteries. d Bone density.

able interindividual variability in the calcium scores, for the entire group the coronary artery calcification-transformed annualized rate was $6.6 \pm 9.7$.

The mean and median coronary artery percentage increase in calcium scores were 17 and $14 \%$, respectively, in the entire group. However, in the 8 patients who showed no evidence of progression, there was a nonsignificant decrease in calcium volumes (mean 9.6\%; median 6.1\%). Interestingly, those in whom the coronary artery calcification did not progress also had a slower rate of thoracic aortic calcification $(\mathrm{p}<0.05)$ compared to those in whom the coronary calcification progressed. The annualized CAC volumes exhibited a modest correlation with the annualized thoracic aorta volumes $(\mathrm{r}=0.61, \mathrm{p}=0.003)$, but not with those of the carotid arteries or L1-L2 vertebral bone density (table 5). There was excellent intra- and interobserver reproducibility in the determination of MDCT vascular calcium volumes and lumbar bone density (table 6).

\section{Discussion}

The present pilot study shows that short-term (60 doses over 5 months) intravenous STS (12.5-18.75 g/treatment 3 times/week) is feasible and fairly well tolerated (with the exception of nausea and vomiting which was controlled by decreasing or avoiding the higher doses). STS treatment showed no overall statistically significant progression of vascular calcification of the coronary and carotid arteries, or of the thoracic aorta. Changes in thoracic aorta calcification, but not carotid arteries, correlated with those of the coronary arteries. There were no adverse effects of treatment on vascular or cardiac structure and function. Furthermore, L1-L2 vertebral bone density remained unchanged with STS treatment in the entire group. However, subgroup analysis revealed progression in 14 of 22 patients. No baseline or treatment variables were associated with progression. 
The use of STS for reduction of vascular calcification is supported by studies reporting efficacy in calcific uremic arteriopathy (CUA), urolithiasis and tumoral calcinosis [13]. Disruption of normal calcium-phosphate homeostasis is considered a primary cause for calciumphosphate deposition in CUA, but this entity can be seen in the presence of normal calcium, phosphate and serum PTH levels [4]. Therefore, other factors can lead to ectopic osteogenesis in the absence of direct calcium/phosphate deposition. STS was first described as an antidote for $\mathrm{cy}$ anide poisoning over 110 years ago. It is also used as a dechlorinator, a modifier of platinum-based treatment toxicity, and a topical treatment for acne and pityriasis versicolor $[4,14]$. In uremic patients, STS may reduce vascular calcification by forming a soluble complex with calcium that lowers free calcium ions, and/or by antioxidant effects (with improved endothelial function and vasodilatation) [14]. STS has unpaired electrons that may scavenge free radicals to stimulate glutathione production (an antioxidant). Moreover, STS may generate hydrogen sulfide which is a vasodilator and has anti-inflammatory properties and analgesic effects.

Although no large, prospective, randomized trials examining the role of STS in reducing vascular calcification have been published, one small nonrandomized study has studied this in HD patients [15]. In this study, 49 patients with a CAC Agatston score $\geq 300$ were enrolled; of these, 16 were selected to receive STS and another 15 comprised a concurrent nonrandomized control group. Patients in the treatment group received $12 \mathrm{~g}$ of STS twice a week after dialysis for 4 months. The authors found that STS treatment was associated with no overall progression of CAC. Only 4 of 16 in the STS group were 'progressors' versus 10 of 15 in the control group. The sole predictor of CAC progression was STS treatment. Similarities between the present and the previous study include the lack of a significant increase in the CAC with STS treatment. In addition, the present study also showed no increase in calcium scores of the thoracic aorta and carotid arteries. Furthermore, vascular and cardiac structure and function were evaluated in the present study and found to not change with treatment. Thus, taken together, the results of these 2 pilot studies provide preliminary data supporting the hypothesis that STS treatment may be effective in decreasing progression of vascular calcification in $\mathrm{HD}$ patients.

The effects of STS on bone density are different in the 2 studies. The present study showed no change in calcium score in the L1-L2 vertebrae, but the hip was not evaluated. In contrast, hip bone mineral density was decreased, but the vertebral spine was not evaluated in the in the previous study. A recent animal study showed that those treated with STS exhibited decreased bone strength compared to placebo [5]. Thus, the effects of STS on bone density are a potentially serious complication that requires further evaluation.

Several other differences between these 2 studies are worth discussing. First, the patient populations are different: a predominantly African-American population in the present study versus a Thai population in the previous. Second, STS treatment in the present study occurred 3 times/week for 5 months versus 2 times/week for 4 months in the previous study. The doses were similar, with STS $12.5 \mathrm{~g} /$ treatment being the predominant dose used in both studies. However, the optimal STS dose and treatment duration remains to be determined.

Studies evaluating progression of established CAC in ESRD patients report annualized increases of 6-104\% [16-22]. Variability in progression with these studies may be due to heterogeneity in design, differences in CT scanner type and scoring systems, dialysis vintage, comorbidities (e.g. diabetes and age), and variation in baseline levels of calcium, phosphorus and PTH. Renal transplantation seems to slow the progression of CAC in the ESRD population, but uremia alone does not explain ongoing vascular calcification [20,23]. Prior studies have demonstrated the effectiveness of statin therapy on reducing CAC progression in those without renal failure: 25-39\% annual progression in the untreated versus $8-15 \%$ in the treated group $[24,25]$. Moreover diabetic status (33\% greater annual progression over nondiabetic subjects) and abdominal obesity are predictive of progression [25].

This work may have important implications for vascular calcification in dialysis patients. First, vascular calcification is associated with high cardiovascular morbidity and mortality. Second, vascular calcification tends to be rapidly progressive. Finally, other than noncalcium-containing phosphate binders, treatment options are currently limited for reducing the rate of vascular calcification.

\section{Limitations}

Neither this study nor the previous one enrolled a prospective, randomized, placebo-controlled, double-blind control group; therefore, a conclusive statement about the risks and benefits of STS treatment cannot be made. Furthermore, the sample size for both studies was small. The randomization of several hundred HD patients to receive prolonged treatment with STS or placebo likely would be 
necessary to attain adequate power in determining STS benefits and risks. Unfortunately, this was beyond our capacity.

\section{Conclusions}

This study shows a statistical overall lack of progression in CAC volumes in patients treated with STS, independent of phosphorus, calcium, fetuin or high-sensitivity C-reactive protein levels, and a significant correlation of CAC score changes with aortic calcium scores. Furthermore, STS treatment is feasible, appears safe and may decrease the progression of vascular calcification in $\mathrm{HD}$ patients. A large multicenter randomized controlled study to test this possibility is warranted.

\section{Acknowledgements}

This study was supported in part by NIH George M. O'Brien Center for Kidney Disease Research grant (P30-DK079333) to Washington University; by the Barnes-Jewish Hospital Foundation (St. Louis, Mo., USA, project ID 01298-0908-01) and by an unrestricted grant from the Genzyme Corp. to Dr. Delmez. This paper was presented in part at the 43rd Annual Meeting of the American Society of Nephrology (November 16-21, 2010, Denver, Colo., USA).

\section{Disclosure Statement}

The authors report no conflict of interest relevant to this work.

\section{References}

1 Collins AJ, Foley RN, Herzog C, Chavers B, Gilbertson D, Ishani A, Kasiske B, Liu J, Mau LW, McBean M, Murray A, St. Peter W, Guo H, Li Q, Li S, Peng Y, Qiu Y, Roberts T, Skeans M, Snyder J, Solid C, Wang C, Weinhandl E, Zaun D, Arko C, Chen SC, Dalleska F, Daniels F, Dunning S, Ebben J, Frazier E, Hanzlik C, Johnson R, Sheets D, Wang X, Forrest B, Constantini E, Everson S, Eggers P, Agodoa L: United States Renal Data System 2008 Annual Data Report. Am J Kidney Dis 2009; 53:S1-S374

-2 Block GA, Raggi P, Bellasi A, Kooienga L, Spiegel DM: Mortality effect of coronary calcification and phosphate binder choice in incident hemodialysis patients. Kidney Int 2007;71:438-441.

-3 Zheng S, de Las Fuentes L, Bierhals A, AshBernal R, Spence K, Slatopolsky E, DavilaRoman VG, Delmez J: Relation of serum fetuin-A levels to coronary artery calcium in African-American patients on chronic hemodialysis. Am J Cardiol 2009; 103:46-49.

-4 Schlieper G, Brandenburg V, Ketteler M, Floege J: Sodium thiosulfate in the treatment of calcific uremic arteriolopathy. Nat Rev Nephrol 2009;5:539-543.

$\checkmark 5$ Pasch A, Schaffner T, Huynh-Do U, Frey BM, Frey FJ, Farese S: Sodium thiosulfate prevents vascular calcifications in uremic rats. Kidney Int 2008;74:1444-1453.

-6 Agatston AS, Janowitz WR, Hildner FJ, Zusmer NR, Viamonte M Jr, Detrano R: Quantification of coronary artery calcium using ultrafast computed tomography. J Am Coll Cardiol 1990;15:827-832.
7 Lang RM, Bierig M, Devereux RB, Flachskampf FA, Foster E, Pellikka PA, Picard MH, Roman MJ, Seward J, Shanewise JS, Solomon SD, Spencer KT, Sutton MS, Stewart WJ: Recommendations for chamber quantification: a report from the American Society of Echocardiography's Guidelines and Standards Committee and the Chamber Quantification Writing Group, developed in conjunction with the European Association of Echocardiography, a branch of the European Society of Cardiology. J Am Soc Echocardiogr 2005; 18:1440-1463.

$\checkmark 8$ de las Fuentes L, Brown AL, Mathews SJ, Waggoner AD, Soto PF, Gropler RJ, DavilaRoman VG: Metabolic syndrome is associated with abnormal left ventricular diastolic function independent of left ventricular mass. Eur Heart J 2007;28:553-559.

9 de las Fuentes L, Gu CC, Mathews SJ, Reagan JL, Ruthmann NP, Waggoner AD, Lai CF, Towler DA, Davila-Roman VG: Osteopontin promoter polymorphism is associated with increased carotid intima-media thickness. J Am Soc Echocardiogr 2008;21:954-960.

$>10$ Subherwal S, de las Fuentes L, Waggoner AD, Heuerman S, Spence KE, Davila-Roman VG: Central aortic pressure is independently associated with diastolic function. Am Heart J 2010;159:1081-1088.

-11 Hokanson JE, MacKenzie T, Kinney G, Snell-Bergeon JK, Dabelea D, Ehrlich J, Eckel RH, Rewers M: Evaluating changes in coronary artery calcium: an analytic method that accounts for interscan variability. AJR Am J Roentgenol 2004;182:1327-1332.
12 Jung HH, Kim SW, Han H: Inflammation, mineral metabolism and progressive coronary artery calcification in patients on haemodialysis. Nephrol Dial Transplant 2006; 21:1915-1920.

13 Papadakis JT, Patrikarea A, Digenis GE, Stamatelou K, Ntaountaki I, Athanasopoulos V, Tamvakis N: Sodium thiosulfate in the treatment of tumoral calcifications in a hemodialysis patient without hyperparathyroidism. Nephron 1996;72:308-312.

14 Hayden MR, Tyagi SC, Kolb L, Sowers JR, Khanna R: Vascular ossification-calcification in metabolic syndrome, type 2 diabetes mellitus, chronic kidney disease, and calciphylaxis-calcific uremic arteriolopathy: the emerging role of sodium thiosulfate. Cardiovasc Diabetol 2005;4:4

- 15 Adirekkiat S, Sumethkul V, Ingsathit A, Domrongkitchaiporn S, Phakdeekitcharoen B, Kantachuvesiri S, Kitiyakara C, Klyprayong P, Disthabanchong S: Sodium thiosulfate delays the progression of coronary artery calcification in haemodialysis patients. Nephrol Dial Transplant 2010;25: 1923-1929.

$\checkmark 16$ Barreto DV, Barreto Fde C, Carvalho AB, Cuppari L, Draibe SA, Dalboni MA, Moyses RM, Neves KR, Jorgetti V, Miname M, Santos RD, Canziani ME: Association of changes in bone remodeling and coronary calcification in hemodialysis patients: a prospective study. Am J Kidney Dis 2008;52: 1139-1150. 
-17 Block GA, Spiegel DM, Ehrlich J, Mehta R, Lindbergh J, Dreisbach A, Raggi P: Effects of sevelamer and calcium on coronary artery calcification in patients new to hemodialysis. Kidney Int 2005;68:1815-1824.

18 Chertow GM, Burke SK, Raggi P: Sevelamer attenuates the progression of coronary and aortic calcification in hemodialysis patients. Kidney Int 2002;62:245-252.

19 Goodman WG, Goldin J, Kuizon BD, Yoon C, Gales B, Sider D, Wang Y, Chung J, Emerick A, Greaser L, Elashoff RM, Salusky IB: Coronary-artery calcification in young adults with end-stage renal disease who are undergoing dialysis. N Engl J Med 2000;342: 1478-1483.
20 Moe SM, O’Neill KD, Reslerova M, Fineberg N, Persohn S, Meyer CA: Natural history of vascular calcification in dialysis and transplant patients. Nephrol Dial Transplant 2004;19:2387-2393.

21 Qunibi W, Moustafa M, Muenz LR, He DY, Kessler PD, Diaz-Buxo JA, Budoff M: A 1-year randomized trial of calcium acetate versus sevelamer on progression of coronary artery calcification in hemodialysis patients with comparable lipid control: the Calcium Acetate Renagel Evaluation-2 (CARE-2) study. Am J Kidney Dis 2008;51:952-965.

22 Tamashiro M, Iseki K, Sunagawa O, Inoue T, Higa S, Afuso H, Fukiyama K: Significant association between the progression of coronary artery calcification and dyslipidemia in patients on chronic hemodialysis. Am J Kidney Dis 2001;38:64-69.
23 Oschatz E, Benesch T, Kodras K, Hoffmann $\mathrm{U}$, Haas M: Changes of coronary calcification after kidney transplantation. Am J Kidney Dis 2006;48:307-313.

-24 Achenbach S, Ropers D, Pohle K, Leber A, Thilo C, Knez A, Menendez T, Maeffert R, Kusus M, Regenfus M, Bickel A, Haberl R, Steinbeck G, Moshage W, Daniel WG: Influence of lipid-lowering therapy on the progression of coronary artery calcification: a prospective evaluation. Circulation 2002; 106:1077-1082.

25 Raggi P, Cooil B, Ratti C, Callister TQ, Budoff M: Progression of coronary artery calcium and occurrence of myocardial infarction in patients with and without diabetes mellitus. Hypertension 2005;46:238-243. 